\title{
Wearable Device in Security
}

\author{
Jo Sung-Gu \\ Department of Protection Science, Kyung-woon Univ., Indeok-ri, \\ Sandong-myeon, Gumi-si, Gyeongsangbuk-do, Korea \\ skcho@ikw.ac.kr
}

\begin{abstract}
Objection of this research is to introduce a development model and a function to secure agents who working in field of protection to VIP, counterterrorism, disaster and safety control, and salvage requiring of brilliant security equipment to increase ability to deal with business. This research tried to give an explanation of purpose of this study by dividing development model into 4 areas.

This device could monitor to confirm concentration, fatigue, mental change, checking life or death also could monitor location of agents through GPS system in real time. These lead finally for increasing business efficiency

In this study, typical case sampling method was used. This is a method which can be claimed that same things can be shown in other cases if somethings were shown in some cases.

Information for objects of study should be specifically provided in this method of study because this study is for specific location, objects, and cases so introduction to location and participant for study were needed.

In this study, academic fields are divided as Security(Protection to VIP, Counterterrorism, Disaster and Safety Control, Salvage), Medicine(Otolaryngology, Neurosurgery, Neuropsychiatry, Ophthalmology) and Engineering(Information Technology, hardware production) and specialists who have over 10 year work experiences or doctoral and philosophy degree and specialists are chosen as fields and then we have sufficient information for study from each participant for 6 months. Finally, results of this study are conformed from participants to secure reliability and validity of results of this study.

I would like to wish this product become popular and helpful to agents on site for security assurance and public order in the future.
\end{abstract}

Keywords: Wearable Device, Protection Device, Monitoring System, Security Device

\section{Need to Study}

The current study began with the questions of why certain problems occur and how to resolve them in the field of social security. In the past, when problems arose, they had been resolved through past experiences. However, this study attempted to resolve the matter by selecting the study subjects and a method of study that would most effectively solve the problems. Moreover, certain conditions were considered to make the study feasible, such as obtaining the data, planning the time, budgeting the expense, and choosing the study subjects.

The need to clearly structure the study question arose because the possibility and practicality to solve the problem may be decreased if the study problems are not clear. Plus, we need to consider how much the results of study could help resolve the problems on site.

Therefore, the purpose of this study is to introduce a development model and its functions with the need of smart security equipment that would secure the lives of agents 
in field such as VIP protection, counterterrorism, disaster and safety control, and sea rescue (salvage) as well as maximize the ability to deal with business on site. Also, we attempt to give an explanation for the purpose of this study in terms of the four areas in which the development model could be applied.

First of all, Korea had provided advanced protection services in large-scale international events like ASEM(Asia-Europe Meeting), APEC(Asia Pacific Economic Cooperation), G20 summit(Group of 20), NSS(Nuclear Security Summit). Recently, Korea protection organizations have been networking with the US, the State of Israel, China, Russia, Hungary, Kazakhstan, Vietnam and others. This can be regarded as development of technology and economic growth in Korea. On the one hand, this may be due to the state of national security in the Korean Peninsula, the world's only partitioned country[1].

Looking into the historical failures of Presidential Security Service, there were the death of first lady Yuk, Young-su (1974) allowed by negligent security checks, the death of former president Park Chung-hee(1979) caused by insanity of Kim Jae-gyu (the head of the Korean Central Intelligence Agency), and the death of former president Roh, Moohyun(2009) accompanied by only one bodyguard.

Second, the first terrorism that involved hostages occurred in Munich in 1972 by the Black September of Al Fatah. The victims were the members of Israel national Olympic team. Police of West Germany killed and captured terrorists alive but as a result, all of 9 hostages were killed. It remains as a typical failure case of counterterrorism. By taking this opportunity, many nations established SWAT team and they have been extended their areas. But international society still has been exposed to various terroristic threats and this phenomenon seems to continue.

When analyzed in terms of the casualties of counterterrorism agents and their causes, it has been insufficient to develop the equipment through the improvement of information reception, radio communication, threat detection, and abilities of individual protection to help counterterrorism agents for securing survivability. Counterterrorism agents should be aware of the operation process to successfully carry the operation. To do so, high-tech equipments are essential. These include sniperscope for searching the location of enemies, two-way radio with the function of warning, and various protection equipments for individual protection.

According to the report in 2014 by Mossad, the secret intelligence service of Israel, current terrorist organizations have been using high-tech weapons. In secret, North Korea and Iran has been teaching Hezbollah and Hamas, the islamic-armed terrorist organizations, how to commit an act of terrorism. In Korea, three hundred computers in Agency for Defense Development(ADD) were hacked in 2014, leaking restricted documents and military secrets.

Third, Osama Bin Laden admitted that 9.11 attack on World Trade Center in New York City was ordered by him. Terrorists committed a hijack of four private airplanes to demolish World Trade Center and Department of Defense in Virginia. After that, the US declared a war on terrorism. Meanwhile, FBI discovered evidence of Bin Laden's involvement in 9.11 atteck and CIA aimed for tracking him down by making new task force teams. As a result, Osama Bin Laden was killed in 2011 by Navy SEAL of the US in Abbottabad, Pakistan.

However, 343 firefighters in operation of saving people in dark had passed away because of 9.11 attack. Accordingly, the safety issue of disaster relief agents had been raised.

Lastly, if a marine accident occurs in the sea, responsible departments of navy and maritime police respond and then operation for lifesaving is conducted. In Korea, the government successfully refloated a North Korean semisubmarine boat, which was sunk by ROKN from 150 meters depth of water in the South Sea in 1999. Additionally, in the sinking of ferry Seohae, ROKN brought the hull and took 302 dead bodies up to the 
surface in 1993 and ROKN have conducted operation in the disasters at sea such as the cruise ship fire in Chungjuho Lake in 1994, Sungsoo Bridge collapse, the plane crash in Jinhaeman Bay in 2001, the firefight helicopter crash in Hapcheonho Lake in 2007, and sinking of Sewol ferry in 2014.

In 2010, Han, Jo-ho, a warrant officer of ROKN, passed away on his duty to search the missing people in the sinking of Cheonan warship. He swept pirates from the sea as one of detached Cheonghae Unit and worked as an instructor for 20 years in UDT/SEAL, training about 2,000 members. That was because no proper safety equipment for underwater rescue workers had not been developed.

These accidents can threaten national security and public order in local community. Even though the importance of safety for rescue workers is stressed everytime rescue workers pass away on their duty but the danger on duty continues to prevail. That is why we attempted to get involved with this research problem.

\section{Development Technique Theory}

Pulse Oximetry and BVP(Blood Volume Pressure) sensors for measuring pulse are using PPG(Photoelectric plethysmo graphy). Oxidised haemoglobin ( $\mathrm{HbO} 2)$ and haemoglobin $(\mathrm{Hb})$ in blood show various spectrum feature when it is given light which has from $500 \mathrm{~nm}$ to $1000 \mathrm{~nm}$. In other words, $\mathrm{HbO} 2$ and $\mathrm{Hb}$ show very different aspects in absorption rate of the light and blood volume which flows in fingers through artery depends on heartbeat. Namely, $\mathrm{HbO} 2$ and $\mathrm{Hb}$ which are proportional in accordance with blood volume, a photodiode turns in proportion to an incident quantity of the light onto output voltage so we can predict pulse by measuring that's result. The GPS equipment can be considered as efficient security equipment which can monitor the site in real time and also can notice agents' survival, physical temperature in emergency situation. In other words, GPS security system can make better security environment. Similar products selling on the market are a pulse measuring instrument, a GPS necklace, a cardiotachometer, a blood pressure measuring device but compound products are not on the market. It can give possibility an example to the current galaxy gear. It is different that's purpose on function and target but if that is developed, possibility is considered higher than ever[2].

\section{Method of Study and Object of Material Collection}

\subsection{Method of Study}

Development for wearable security equipment is a new topic for national security in 21 century and this is abilities to come up with idea faster than others [3].

This study take on the character of exploratory research because this object has not been conducted so far and in case of exploratory approach like this case, a qualitative research method is better than a quantitative research method because qualitative research is different to a quantitative research which is determined on design for research before study and qualitative research can be adjustable and modifiable for schmear on study even in processing of study[4].

In this study, a qualitative research method help choose these following: "What subject for inquiry can be selected?", "What object will be selected for answer to subject for inquiry?", "What kind of interview guideline will be effective?", "Is interview method appropriate with participants?", "Is method of analysis appropriate to use collective data?"[5].

In a qualitative research, researchers should consistently have conversation with study participants to understand their emotion, awareness. This method means researchers have 
research attitude to endeavor to question, answer, think, discuss, gain the sympathy and impetus[6].

If researchers do like that, study participants make effort to show and understand their own life to researchers. In this respect, a qualitative research depends on how much researchers are close to study participants because familiarity between study participants and researchers makes quality of data.

We had established a close rapport with study participants to conduct this study successfully before data collection and data analysis work start so we can expect to have a positive effect on processing of interview. Lower Table 1 shows processing of research.

Table 1. Processing of Research

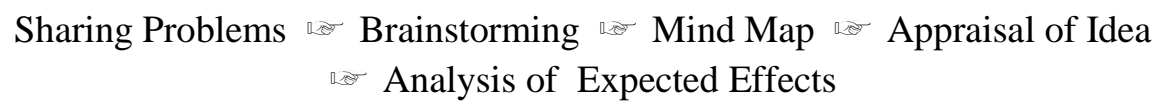

This study was conducted for 6 months. Generally, researchers finish data collection and then analysis data but in this study, data analysis and data collection were conducted rotationally. In other words, data was analyzed immediately after have interview and then new question was applied.

Interview was conducted in participants' office and the interview lasted for 45 minutes to 60 minutes each but sometimes it took 90 minutes. Interview was recorded by a digital recorder and then contents of the conversation were analyzed by doing transcript after interview.

\subsection{Object of Material Collection}

In this study, typical case sampling method was used as a appropriate method of research. This is a method which can be claimed that same things can be shown in other cases if something's were shown in some cases.

If we can know kinds of problems are in accident, other accidents can be prevented. That means some portions can represent the others. That's called targeted sampling. in order to do targeted sampling, this study had interviewed.

The materials which were collected like that way conducted until appropriate idea and basis for research purpose were found as saturated sampling. This means a study lasts until new information are not found anymore and that basis were defined by sufficient redundancy. Lower Table 2 shows specialists as academic fields in this study.

Table 2. Specialists as Academic Fields

\begin{tabular}{|c|c|c|}
\hline \multirow{4}{*}{ Security } & $\begin{array}{c}\text { Protection to } \\
\text { VIP }\end{array}$ & $\begin{array}{c}\text { secretary of Presidential Security Service } \\
\text { Ph.D in Security Administration }\end{array}$ \\
\cline { 2 - 3 } & Counterterrorism & $\begin{array}{c}\text { a bureau-chief-grade official of NIS } \\
\text { Ph.D in criminology }\end{array}$ \\
\cline { 2 - 3 } & $\begin{array}{c}\text { Disaster and } \\
\text { Safety Control }\end{array}$ & $\begin{array}{c}\text { a deputy director of } \\
\text { Ministry of Public Safety and Security } \\
\text { Ph.D in science of public administration }\end{array}$ \\
\cline { 2 - 3 } Medicine & Salvage & master sergeant of Ship Salvage Unit(ROKN) \\
\hline \multirow{4}{*}{} & Otolaryngology & $\begin{array}{c}\text { a specialist of } \\
\text { Seoul National University Hospital }\end{array}$ \\
\cline { 2 - 3 } & Neurosurgery & $\begin{array}{c}\text { a specialist of } \\
\text { Kyungbuk National University Hospital }\end{array}$ \\
\cline { 2 - 3 } & Neuropsychiatry & $\begin{array}{c}\text { a specialist of } \\
\text { Yeungnam University medical center }\end{array}$ \\
\hline
\end{tabular}




\begin{tabular}{|c|c|c|}
\hline \multirow{3}{*}{ Engineering } & Ophthalmology & $\begin{array}{c}\text { a specialist of } \\
\text { Yeungnam University medical center }\end{array}$ \\
& Information & a researcher of \\
& Technology & Samsung Electronics Research Institute \\
& Hardware & Ph.D in engineering \\
\cline { 2 - 3 } & Production & $\begin{array}{c}\text { a researcher of Samsung Techwin } \\
\text { Ph.D in engineering }\end{array}$ \\
\hline
\end{tabular}

As Table 2, information for objects of study should be specifically provided in this method of study because this study is for specific location, objects, and cases so introduction to location and participant for study were needed.

In this study, academic fields are divided as Security (Protection to VIP, Counterterrorism, Disaster and Safety Control, Salvage), Medicine(Otolaryngology, Neurosurgery, Neuropsychiatry, Ophthalmology) and Engineering (Information Technology, hardware production) and then specialists who have over 10 year work experiences or doctoral and philosophy degree and specialists are chosen as fields.

\section{Function of Device}

This device is designed to check oxygen saturation for monitoring a concentration, fatigues, an abnormal mental state, and the living or the dead, also is equipped with GPS system for monitoring locations in real time. Figure 1 shows a prediction model of research.

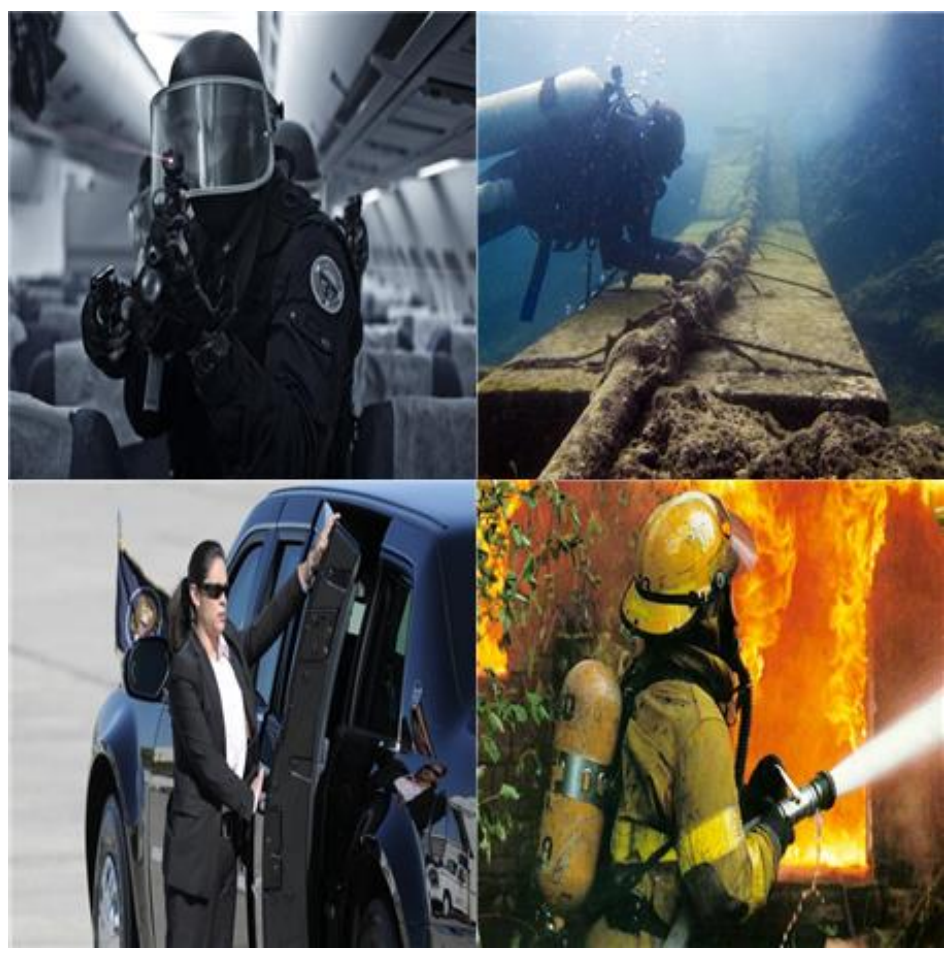

Figure 1. Predicted Model of Study

※These pictures are from Google.com

\subsection{Escort}

Looking at protection history of Korea, military power was used to protect VIP from the thread of war. In 1948, the first President, Rhee Syngman, established police station 
within the Blue House to protect Rhee Syngman's family. This is the origin of modern protection in Korea. A Specialized protection agency was made in 1963 when Third Republic established after May military coup d'etat.

In light of cases in the past, the success of protection depended on one or two bodyguards and the cause of failure was their acts. If these fundamental issues were not solved, it will be hard to prevent an attack.

Generally, bodyguards carry out a mission with lots of stress. Even though they are ready to meet any possible contingencies that may arise in terms of prevention, accidents could be happened. they take all responsibility of failure.

Accordingly, a command post should check a mental and physical condition of assigned bodyguards to site through checking oxygen saturation and monitor location change of the agents in real time through GPS system.

\subsection{Counterterrorism}

Since 1989, After the Cold War between the US and the Soviet Union was ended, concept of national security in international society has been changed from security in military characteristics to comprehensive security and a typical example is terror as a part of asymmetric warfare capabilities.

Today, international societies including the UN have come up with countermeasures for preventing terror but they don' t work. There are 195 countries which experienced terror from 1968 to 2010[7].

Accordingly, each country has increased the number of counterterrorism agencies and has modernized counterterrorism equipment but the equipment, which has effectiveness, has not been developed.

Agents for counterterrorism are commonly stressed on operation failure because it bring about casualties by terrorists.

Therefore, a command post should check a mental and physical condition of assigned bodyguards to site through checking oxygen saturation and monitor location change of the agents in real time through GPS system.

\subsection{Disaster and Safety Control}

Every time grand scale disasters happen by conflagration, government authorities come up with countermeasures of various kinds but as time goes by, similar safety accidents happen without fail.

In other aspects, investment for disaster and safety control has been poor because of characteristic which have to pay manpower, time to unrisen accidents and until now, equipment for safety of firefighters has not been developed.

Additionally, post-traumatic stress disorder of firefighters are three times it of police in charge of violent crime and incidence of death for firefighters have been increased as insufficiency of protective gears.

Accordingly, a command post should check a mental and physical condition of assigned firefighters to site through checking oxygen saturation and monitor location change of the agents in real time through GPS system.

\subsection{Sea-Rescue Work}

Performances by ship salvage units(SSU) in current incidents which are about corvette Cheonan(2010), Sewol ferry(2014) made us impressed.

In process of searching persons who were missing on naval vessel Cheonan, warrant officer Han Juho, ROKN was died on duty and in process of searching persons who were missing on ferry Sewol, an engineer diver who was attached to 88 Underwater Development which is a private company was died on duty. 
Engineer divers in principle should submerge one time and then take a rest a day and operation time is around 10minutes and when they come up to surface of the water, they have to come up at a speed of 9 meters per hour but in sea-rescue work, they had no choice to submerge 3times a day.

Accordingly, a command post should check a mental and physical condition of assigned firefighters to site through checking oxygen saturation and monitor location change of the agents in real time through GPS system.

\section{Opinions from Experts for Results of Study}

- "High tech tools which detect security risks through heat detector by checking change of pupils of the eyes exist in some events in the Blue House but until now, monitoring equipment which is to check psychological and physical change by utilizing oxygen saturation doesn't exist so I think, It will be very useful protection equipment....." (KHS, a secretary of Presidential Security Service).

- "Monitoring on agent by utilizing GPS system is needed to counter-terrorism and Alert Order....." (LCH, a Senior Inspector of the SWAT team).

- "There is nothing wrong with that tools to be commercialized and this tools which utilize high-tech IT technology can be preventive of danger of agents who is related on national security" (HHS, a researcher of Samsung Techwin).

- "If vital signs of agents can be used to check psychological change and physical danger of agents, a command post can decide and take action immediately." (LSY, a specialist of Seoul National University Hospital).

- "There is nothing like this gear so far as I know" (JYS, a bureau-chief-grade official of Counterterrorism Center in the National Intelligence Service).

\section{Conclusion}

The purpose of this study is that important to have integrated safety regulations in general considering the fact of large event halls a fact which many citizens are participate in. Getting cooperation from the department involved comes to the fore critical issues as well as actions of police and private security[8].

Recently, diversified society structures and environments demand high-level public peace to the government. In the other hand, threats to society are getting diversified [9].

Specifically, the time, place, way of terror are decided by a terrorist and the protection agents can only prevent because ultimately, the follow-up measures after contingency mean protection failure [2].

Therefore, purpose of this study is to introduce development model and function to secure agents in field of protection to VIP, counterterrorism, disaster and safety control, salvage through need of smart security equipment to increase ability to deal with business. We should attempt to give an explanation of purpose of this inquiry by dividing development model into 4 areas [10].

This is a device for monitoring to confirm concentration, fatigue, mental change, checking life or death through checking and also it' $\mathrm{s}$ finally for increasing business efficiency by monitoring position of agents through GPS system.

The Clinton administration of the US decided to open GPS technology which is limited as purpose of military operation only to the public, so the public can get exact coordinate information. After that, GPS technology has been used like navigation system, application in smart phone so the present, GPS system has been a part of our life. Specially now, using of smart phone has been popularized and various smart phone applications which provide longitude and latitude coordinate information are provided for free so interest of the public is getting higher for using location information [11]. 
In this study, reliability and validity of result of study are regarded positively by top experts in Korea.

I would like to see what this product is become popular and then become helpful to agents on site for security assurance and public order in the future.

\section{References}

[1] K. Dong-Je and J. Sung-Gu, "Security, BAEKSAN, Seoul (2013).

[2] J. Sung-Gu and K. Dong-Je, "Smart security, Need for security equipment development", Journal of Korean Society of Private Security, vol. 13, no. 3, (2014).

[3] K. Eun-kyung, "Training How To Think Creatively", HANBITACADAMY, Seoul, (2014).

[4] K. Yeong-Cheon, "Qualitative Research Methodology I", MOONUMSA, Seoul, (2007).

[5] J. Sung-Gu and L. Ju-Lak, "The Challenges of the Court Security Team", The Journal of Korean Association of Security and Safety, vol. 7, no. 1, (2011).

[6] D. Jorgensen, "Participant observation: a methodology for human studies", SAGE, California, (1989).

[7] C. Jin-Tae, "The principles of counterterrorism", DAEYOUNG co, Seoul, (2011).

[8] K. Tae-Min and J. Sung-Gu, "The Methods to Develop Operating Private Security in Large Event Halls", The Korean Association of Police Science Review, vol. 13, no. 1, (2011).

[9] J. Sung-Gu, K. Haw-Su and K. Dong-Je, "A Study on the Public Security Service Techniques of Select the Type", Proceedings of The 2012 Green Safety City and Crisis Management, Cheong-ju, Korea, (2012) September 21.

[10] J. Sung-Gu, "Wearable Monitoring Device in Security", Proceedings of the 6th 2015 International Interdisciplinary Workshop Series, Je-ju, Korea, (2015) April 15-18.

[11] K. Min-Sung and C. Je-Yeng, "Development and Application of a Geographic Learning Model Using Smartphone GPS", Social studies education, vol. 51, no. 3, (2012).

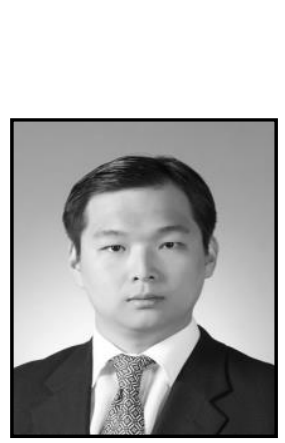

\section{Author}

\section{Sung-Gu, Jo}

A protector to the President of Korea, Geun-hye, Park.

A professor of department of Protection Science in KyungWoon University, Korea.

A secretary general of Korean Association for Public Security Administration.

An executive of The Korean Society of Private Security.

An extraordinary member on disaster and safety of The Korean Association for Policy Studies.

A planning director of Korean Police Studies Association.

A Planning director of The Korean Association for Crisis and Emergency Management.

An educational director of The Convergent Research Society Among Humanities, Sociology, Science, and Technology.

A question designer of a qualifying examination (Protection area) of personal guard.

An instructor of the state registered bodyguard training (In emergency and escort formation).

An instructor of normal and special security instructor training (newly-appointed and qualification training). 